\title{
Ethiopia`s Ongoing Criminal Justice Reform: Modus Operandi, Methodology and Observations
}

DOI http://dx.doi.org/10.4314/mlr.v14i2.6

\section{Abstract}

Muradu Abdo *

This Comment relates to activities undertaken by the Criminal Justice Working Group (WG) under the auspices of the Legal and Justice Affairs Advisory Council (AC). It covers the period between 17 August 2018 and December 2020. The Comment highlights factors calling for reform of Ethiopia's criminal justice, institutional arrangement for the ongoing legal and justice reform in Ethiopia and three principal tasks carried out by the WG. It also briefly forwards issues of concern and expression of gratitude.

\section{Key terms}

Criminal justice $\cdot$ Law reform $\cdot$ Criminal Procedure $\cdot$ Evidence $\cdot$ Prisons

\section{Citation:}

Muradu Abdo (2020), 'Ethiopia`s Ongoing Criminal Justice Reform: Modus Operandi, Methodology and Observations', 14 Mizan Law Review 2: 341-356.

\section{Introduction}

In July 2018, Professor Tilahun Teshome, who was then in charge of putting together various law reform working groups, approached me to assume coordination of the affairs of the Criminal Justice Reform Working Group (WG) under formation. The first question I asked him was to mention names of experts who assented to join the WG. He mentioned names. I realized that

\footnotetext{
* Muadu Abdo (PhD), Associate Professor, Addis Ababa University School of Law Email: muradu1@yahoo.co.nz

ORCID: https://orcid.org/0000-0003-3725-3581

Frequently used acronyms

AC Legal and Justice Affairs Advisory Council

AG Attorney General

CPEC Criminal Procedure and Evidence Code

HoPR House of Peoples Representatives

WG Criminal Justice Reform Working Group
} 
everybody else would be an expert in the field in one way or another. I would be the only soul in the team who would not be a specialist in criminal justice. The only acquaintance I had with criminal law was courses that I had taken close to twenty years ago at the Law School, leaving me with only a faint memory of the area.

My professional passion lies in elsewhere. Yet, Professor Tilahun presented the matter in a way that would give little chance for me to decline. I focused largely on the governance side of the WG, leaving my discomfort zone of criminal justice to my good colleagues. Even after working with the WG for well over two years, I still remain adamant about my smatter of knowledge of criminal justice. At any rate I have been honored to serve in this capacity. The experience has given me the opportunity to make new friends and acquaintances. That remains close to my heart forever.

\section{The Need for Reforming Criminal Justice System in Brief}

Dr. Abiy Ahmed, upon swearing in as a prime minister in April 2018, initiated a spate of reform measures broadly regarded as opening up the political, economic and justice arenas. His administration characterized the justice reform endeavors of its predecessor as a fiasco due primarily to lack of genuine participation of the public and pertinent professionals, vowing to rectify these alignments. Issues in Ethiopia's criminal justice system, and violent and repressive recent past went far beyond the absence of public and expert participation pre-existing reform process. There have also been outcries regarding major defects in design, compliance and implementation of the substantive, procedural and institutional components of criminal justice of the nation as a whole with a material impact on the rule of law, institution building, human rights, democracy and federalism.

\section{Mandate of the Working Group}

As an endeavor to overhaul the justice sector, the Federal Attorney General (AG) set up the Legal and Justice Affairs Advisory Council (AC) composed of academics and lawyers in June 2018. The overall responsibility of the AC is to advise the Government of Ethiopia both on the design and implementation of legal and justice sector reform. In order to discharge this responsibility effectively, apart from a secretariat, the $\mathrm{AC}$ has formed several working groups composed of professionals drawn from law and related fields.

The Criminal Justice Working Group (WG) is one of such working groups. The WG is presently composed of 23 independent academics and practitioners drawn from law and other disciplines to provide pro bono 
service. ${ }^{1}$ Former judges and prosecutors, law teachers, researchers, human rights advocates, consultants, practicing lawyers, social work experts, and lawyers cum criminologists form part of the WG. Its formation was formally announced on August 17, 2018 with the mandate to work on assignments including initiating or reviewing draft laws which the $\mathrm{AC}$ might refer to it and undertaking diagnostic studies in the area of criminal justice system with a focus on the police, prosecution, judiciary and penitentiary system taking into account constitutional and international standards, state policy objectives and global good practices ${ }^{2}$.

The WG set itself to actual work forthwith with a work plan which enabled it to organize itself to (i) sub-working groups, expand and strengthen its membership and volunteer base ${ }^{3}$, (ii) fix a date and regular venue for regular bi-weekly meetings and share resources among members, (iii) reach a shared understanding of the mandate of the WG as embodied in the TOR and (iv) finding modalities of creating institutional linkages and reform alignments. ${ }^{4}$

${ }^{1}$ At present the members of the WG are: Ato Abraham Ayalew, Ms. Bieza Nigussie, Ato Cherinet Hordofa, Dr. Dagnachew Assefa, Ato Eyob Awash, the late Major Fekadu Tolera, Dr. Meseret K. Desta, Dr. Muradu Abdo, Ato Nuru Seid, Ato Shebru Belete, Dr. Simeneh Kiros, Ms. Tedenekialesh Tesfa, Dr. Wondemagegn Tadesse, Ato Yoseph Amero, Dr. Marshet Tadesse, Ms. Akilile Solomon, Ms Eyerusalem Teshome, Ato Worku Yaze, Dr. Alemu Meheretu, Ato Betemariam Alemayehu, Ato Abdulkader Mohammed, Ato Kelemework Mideksa and Ato Daniel Aregawi while the volunteers are Dr. Wondowssen Demissie, Dr. Elias Nour, Ato Adi Dekebo, Dr. Abdi Jibril, Dr. Commander Demelash Kassaye, Ato Tibeso Bezabeh and Ato Desalegn Kebede.

2 As per the TOR, the specifics of the tasks of the WG are to: adopt evaluative frameworks, which means constitutional and international standards, policy objectives and best practices relevant to its thematic area; undertake diagnostic studies on the basis of the evaluative frameworks; conduct public consultations on the findings and recommendations of the diagnostic studies; prepare draft laws (where necessary) based on recommendations emanating from the diagnostic studies and prepare background document where drafting new or revised law is thought necessary.

${ }^{3}$ The WG's membership expansion initiative brought on board Dr. Marshet Tadesse, Ms. Akilile Solomon, Ms Eyerusalem Teshome, Ato Worku Yaze, Dr. Alemu Meheretu, Ato Kelemework Mideksa, Ato Betemariam Alemayehu, Ato Abdulkader Mohammed and Ato Daniel Aregawi.

${ }^{4}$ Personal observations, experience and quick scanning of Ethiopia's criminal justice sector helped members of the WG learn the existence of ongoing reform initiatives in institutions such as the federal correctional administration. The WG also realized that the existence out there of vital documents (e.g., draft laws, reform reports, codes of conduct for and organizational structures) in possession of pertinent government institutions but might be difficult for the WG to get access those documents. Hence in 


\section{Three Core Activities and modus operandi of the WG}

The WG has so far made three contributions to the reform of criminal justice system of Ethiopia.

\section{a) Reviewing a Draft Prison Proclamation:}

The WG's first contribution was to overhaul a draft Prison Proclamation prepared by experts of the Federal Prison Administration (FPA), currently Federal Prisons Commission. The draft was meant to revise about fifteen years old prison law. Upon receiving the draft prison bill, the WG set up an ad hoc sub-working group to look into it. ${ }^{5}$ The sub-working group's cursory reading of the draft proclamation revealed it was much to be desired in terms of protecting the dignity and human rights of prisoners as well as their rehabilitation and reintegration. However, it was short of contemporary constitutional, continental and global standards and good practices regarding the treatment of prisoners and rearrangement of prison as an institution. Notably, the sub-working group realized that even if the draft presented by the FPA contained innovative ideas concerning operational and financial autonomy of the institution, it nevertheless was crafted from the perspective of easing the functions of the prison administration through custodian

order to avoid duplicity of efforts, to obtain relevant documents and information timely and to pave the way for smooth implementation of reform measures and efficient discharge of its responsibilities, the WG needed to have some kind of working relation with these institutions. This included creating mechanisms of reaching out to regional law enforcement institutions as well as pertinent professionals based in the regions. The working relation forged assumed different forms. The first form involved just writing a letter of cooperation to the institution concerned. This in particular involved in the AC Secretariat writing standing letters of cooperation, for instance, to most relevant federal criminal law enforcement institutions to provide information and pertinent documents. The second method was identifying and designating a focal contact person in each key institution to generally facilitate communication of the WG with that institution and particularly to provide it with information. The third modality, which the WG thought to be the preferred one, was creating workable institutional relation that should go beyond getting data. It envisaged a kind of relationship characterized by embedded independence -making a relevant person formally part of the WG from the outset without compromising the independence of the WG. This should perhaps be preceded by a formal briefing of the mandates of the AC and the working groups set up under it to a set of main government institutions. The WG used this last method to some degree. This method further entailed mapping stakeholders both within and outside government institutions to help align the reform initiatives in the criminal justice sector with the works of the WG and identify available resources.

${ }^{5}$ The main movers of this assignment were: Ato Cherninet Hordofa, Ato Abdulkader Mohammed and Ato Yalelet Teshome. 
approach rather than building on an approach which ensures the human rights of prisoners, rehabilitation and reintegration.

The WG had to bring the experts and leadership at the FPA on-board in the course of changing the orientation of the draft law. Yet, that had to be accomplished cautiously without antagonizing them because it would be the FPA who would defend the draft law during the discussion and consultations in the legislative process and that would implement it upon enactment as proclamation. The WG was able to bring them on board asking them to rewrite the draft jointly. Fortunately, they were quite willing and receptive of key changes. Thus, exchange of views with the experts and top leadership of the FPA ensued quickly. In the shortest possible time the draft was transformed beyond recognition.

The WG convened two meetings to deliberate on the draft legislation. Those members of the WG who were unable to attend such meetings turned in written comments. The WG also held a consultation with the AC to enrich the draft statute. The joint deliberations made between the WG, and FPA experts and officials, between the $\mathrm{WG}$ and $\mathrm{AC}$ validated and considerably improved the draft law. Hence, those exchanges of thoughts helped the draft bill sail through the legislative process -from the AG all the way to the House of Peoples Representatives. In the end, the law has been enacted in the Federal Negarit Gazete as the Federal Prison Proclamation 1174 of 2019.

It is hoped that this prison legislation would serve as a stepping stone to overhaul regulations, directives and rearranging institutional structures of the federal penitentiary system. It is also hoped that regional correctional administrations would emulate it. Above all, the bill would hopefully help the entrenchment of the dignity of prisoners, their rehabilitation and reintegration.

\section{b) Reviewing a Draft Criminal Procedure and Evidence Code:}

The second task of the WG was to rework the draft Criminal Procedure and Evidence Code (CPEC) which is intended to revise well over half a century old Criminal Procedure Code. This time around, the WG also created an ad hoc sub-working group consisting of some of its highly knowledgeable and experienced members to revisit the draft CPEC. ${ }^{6}$ Even if such a sub-working group took upon itself primary responsibility, every other member of the WG was tasked to go through the document for suggestions. The subworking group members rose to the occasion. The sub-working group as

${ }^{6}$ Dr. Alemu Meheretu, Ato Cherinet Hordofa, Dr. Simeneh Kiros, Ato Kelemework Midkesa and Ato Yalelet Teshome were part of the special team. 
well as the rest of membership reviewed the draft CPEC to check whether it has:

i. reflected constitutional principles including federalism,

ii. integrated into one coherent whole the various criminal procedure related statutes passed for the last several decades,

iii. included principles and rules of evidence relevant to criminal proceedings and provisions meant to humanize the death penalty,

iv. conformed with continental and international human rights standards and good practices,

v. incorporated issues such as reconciliation, customary criminal rules and institutions and plea bargaining to ease court burdens and ensure the efficacy and legitimacy of criminal proceedings,

vi. taken into account the need to abolish practices observed at the various stages of criminal proceedings with the effect of hampering the rights of the suspects, accused and convicted,

vii. eliminated outdated provisions and

viii. ensured completeness and clarity.

Having undertaken a preliminary review of the draft document in light of the preceding points, the WG organized a-two-day workshop in Addis Ababa for an in-depth review. The event focused broadly on the document's conformity to international and constitutional standards, contextualization, completeness, clarity and simplicity of arrangement. The findings of this WG level workshop were incorporated in the draft document.

The in-house scrutiny was followed by another two-day Bishoftu workshop at which members of the WG, those of the AC and experts drawn from the federal police, prosecution, judiciary and penitentiary, scholars and practicing lawyers attended. Quality feedback was obtained from the event. Again the special sub-working group reflected on the findings and recommendations of the Bishoftu consultation in the draft bill. ${ }^{7}$ This was

\footnotetext{
${ }^{7}$ In the course of the revision, the WG took into account feedback generated during our March 16 retreat at Jupiter International Hotel, inputs gathered from the joint discussions the WG had with the AC (12-14 April) in Bushoftu, comments and suggestions forwarded to the WG by Setaweet on May 22 and those forwarded subsequently from representative of the Ethiopian Women Lawyers Association as well as the Women and Children Affairs Department of the Office of the Federal Attorney General. The team also consulted a specialist in and long-time serving federal court judge with regard to juvenile offenders' treatment chapter of the CPC. Needless to say, that the draft benefited immensely from the mix of knowledge and experiences of members of the focal group - judicial, teaching, research, prosecutorial, court practice and legal drafting. The several expert presentations organized by the
} 
followed by the WG's formal submission of the reworked draft CPEC to the $\mathrm{AG}^{8}$ which in turn submitted it to the Council of Ministers after conducting final in-house review. The Council of Ministers, which apparently deliberated on an Explanatory Note rather than on the actual draft CPEC in its entirety, sent it to the House of Peoples' Representatives (HoPR) in the summer of 2020. After the first reading of the HoPR, the draft CPEC was (on October 8, 2020) referred to the Legal, Justice and Democracy Affairs Standing Committee for further scrutiny. The HoPR will hopefully enact it in one of the upcoming sessions. In addition to HoPR's standing committee level review, it is hoped that this last leg of the legislative process would trigger public consultations, both public and institution based, as well as provide some opportunity for the $\mathrm{WG}$ to further improve the document which is hoped to serve the nation for the coming decades.

\section{c) Conducting a diagnostic study}

Undertaking a diagnostic study is the third core accomplishment of the WG. Despite tight involvement in the above two bill making processes, the WG returned to and completed the criminal justice system assessment study. To this effect, the WG developed terms of reference.

The WG thought that the assessment study is called for good reasons, which are articulated in the terms of references. Some highlights here (of the terms of reference for the diagnostic studies) would be sensible. Firstly, the WG concluded that the ongoing reform should build on an inventory of criminal justice system reforms attempted so far -what has worked well, what has not, and why. That kind of comprehensive inventory dedicated exclusively to past reform initiatives as well as assessing the present state of the criminal justice system of Ethiopia is lacking. Literature review conducted by the WG reveals that past reforms and studies in the area remain piecemeal, outdated, and fragmentary and hence unable to provide a full picture of the criminal justice system of Ethiopia.

\footnotetext{
WG on the different dimensions of the criminal justice system of our country also played no fewer roles in the revision process. Hence, the synthesis of all this was injected into the latest rendition of the document meant to serve the country for the coming decades. Such synthesis has served to produce a better document in terms of inclusiveness of multifarious interests and voices, contemporary thinking in criminal procedure, and putting together fragmented rules and principles coherently in a single document and drafting technicalities.

8 The WG received the Draft CPEC from the AG on 23 February 2019, and the WG submitted its final revised draft to the AG on June 22, 2019.
} 
Secondly, it is necessary to identify major reform issues, their nature and scope methodically. Thus, rather than rushing to utilize one or another reform tool, the study helped identify whether a problem relates to law design, compliance with the law and court decisions or quality implementation of the law or a combination thereof to make recommendations accordingly.

Thirdly, there is a need to come up with basis for prioritizing the principal reform issues - which should come first in the order of things. Fourthly, it is suggested to identify reform matters which can go for implementation in the form of quick wins or those needing legislation or administrative measure or those warranting in-depth study. Finally, as international experience tells, opting for a diagnostic study of this sort is a wise course of action to kick-off informed law or institutional reform initiative.

The above reasons in essence boil down to the need to base the reform of the criminal justice system on empirical data, a systematic and methodologically sound analysis of its strengths and shortcomings, and a comparatively and theoretically informed decision-making with regards to what needs to be done. The diagnostic study falls under the rubric of 'Reforming the Criminal Justice of Ethiopia'. It has covered the following seven topics.

While the ultimate responsibility of the integrity of each diagnostic study lies in and credit goes to the WG as a whole, it is customary to mention the principal researchers for each topic, which is indicated in the parenthesis against each topic.

i. Evaluating the Existing Criminal Law: Proposed Subjects and Manners of Revision (Dr. Simeneh Kiros),

ii. Ethiopian Federal Police Reform in the Context of Criminal Justice (Dr. Alemu Meheretu),

iii. Assessment of the Prosecutorial Role and Functions in Ethiopia (Ato Adi Dekebo),

iv. Prison Reform in Ethiopia: Normative Gaps, Challenges in Practice, and Recommendations (Dr. Wondemagegn Tadesse),

v. Assessment of the Ethiopian Judiciary (Ato Yalelet Teshome),

vi. Dealing with the Legacies of Repressive Past: Transitional Justice in 'Transitional' Ethiopia (Dr. Marshet Tadesse) and

vii. Compensation for Human Rights Violations in Criminal Proceedings in Ethiopia: Legal and Institutional Framework (Dr. Abdi Jibril). 
More than two years of data gathering ensued. The WG collected data by: i. inviting around eight experts ${ }^{9}$ to its different sessions to learn from their knowledge, experience and expertise as captured through documentation of their presentations and deliberations that ensued;

ii. receiving written comments from professionals ${ }^{10}$;

iii. gathering pertinent legislation, documents, reports and literature in the field which culminated in literature review workshop and proceedings thereof ${ }^{11}$;

iv. gathering empirical evidence through focus group discussions with key informants drawn from different criminal justice institutions ${ }^{12}$;

v. getting information from officials and criminal justice experts during revision of the Prison Proclamation and the CPEC highlighted above;

9 The names of and dates of presentations by the experts are as follows: Ato Mandefrot Belay (22 December 2018) spoke on the intricacies of the 2005 comprehensive justice sector reform; Dr. Elias Nour (8 December 2018) talked about findings of recent research evaluation of the comprehensive justice sector reform; Ato Worku Yaze (16 February 2019) briefed the WG the criminal law practices and processes regarding police, prosecution and courts in the Ethiopian setting; Ato Abraham Ayalew (12 October 2019) presented on recent reform initiatives in respect of juvenile justice, crime prevention strategy, etc.; Ato Abdulfetha Abdullah (12 October 2019) focused on traditional criminal justice in Ethiopia; Ato Adi Dekebo (25 May 2019) considered the prosecution as an institution tied to human rights and police oversight function, the late Major Befekadu Tolera (2 March 2019) addressed the inner sides of police crime investigation; and Ms. Loza Tsegaye from Setawit (25 May 2019) presented on gender based violence in the context of Ethiopia's criminal justice system of today. All of these speakers shared their slides with the WG and the deliberations were recorded as minutes.

${ }^{10}$ For instance, the WG received written comments from Dr. Wondwossen Demissie (Addis Ababa University, School of Law) and Ato Abebe Assefa (Dean, School of Law, Gondar University).

11 A-two-day literature review workshop was held at Getfam Hotel, August 31 and September 1, 2019.

${ }^{12}$ On 3 November, FGD was held at Kaleb Hotel, which brought together federal court judges, prosecutors, investigating police officers, those working at Federal Public Defenders` Office, practicing lawyers, human rights advocates and experts working at the Federal Prison Administration. The key informants were categorized into four groups and the proceedings thereof documented and used as an input for the diagnostic studies. 
vi. conducting internal WG level virtual consultations on the first drafts of each of the studies ${ }^{13}$ and

vii. convening public consultation. ${ }^{14}$

Having collected data and materials needed to draft the diagnostic study using methods enumerated above, the WG moved to data analysis and writeup. The write-up part of the work was carried out by seven selected members, as indicated above, drawn from the WG based on their especial expertise and exceptional dedication to the success of the reform. ${ }^{15}$

The special team embarked upon drafting an assessment report which covers the entire criminal justice system of Ethiopia including national and international substantive, procedural criminal laws, pertinent institutions and their practices. Institutionally the study covers the police, the prosecution, the judiciary, and the prison system; it has also included such kindred areas such as core issues of compensation for violation of human rights in criminal proceedings and translational justice. Thus, the team analyzed, synthesized and interpreted the data listed above and collected supplementary data and identified major problems in Ethiopia's criminal justice system and recommended implementation modalities and indicated reform issues which require institutional capacity building, institutional rearrangement, enactment of legislation and taking administrative measures or conducting in-depth studies.

The underlying common assumption behind the seven research reports is that where a country's substantive and procedural criminal laws are designed appropriately, complied with fully, and consistently and implemented as intended, the criminal justice system of such a country can meaningfully contribute to the prevalence of the rule of law, human rights and democracy. The broader finding of the research reports is that the existing criminal justice system of Ethiopia shows significant deficits in all the three counts:

13 The in-house consultations went as follows; 10 August 2020 was dedicated to the presentation of diagnostic studies on substantive criminal law, and compensation for human rights violations which occur during criminal proceedings; on 18 August 2020 two presentations prosecution and transitional justice were organized; on 29 September, 2020 a presentation on prison reform was conducted; on October 19, 2020 a presentation on Federal Police was made and on October 26, 2020 assessment research on Ethiopia`s judiciary was delivered.

14 That took place on 21-22 November 2020 at Mado Hotel brought together participants from the judiciary, prosecution, prison commission, federal police, civil societies and lawyer community.

15 Dr. Simeneh Kiros, Dr. Wondemagegn Tadesse, Dr. Marshet Tadesse, Dr. Alemu Meheretu, Ato Adi Dekebo, Dr. Abdi Jibril and Ato Yalelet Teshome. 
there are (i) normative design defects, (ii) non-compliance with criminal principles and rules and court decisions, and (iii) implementation gaps. The combination of these shortcomings makes Ethiopia`s current criminal justice system below constitutional and established international human rights standards. Thus, this calls for a concerted action on the part of relevant actors to remedy these deficits by taking legislative, administrative and institutional reform measures in line with the recommendations.

Another common thread that runs through the diagnostic study is a focus on the institutional side of criminal justice. The WG assumed that identifying the deficiencies of the institutional dimensions of the criminal justice system of Ethiopia and forwarding appropriate strategies would be more relevant. The WG assumed that a robust institutional element, if put in place rightly, would take care of the normative side of the criminal justice system reform.

The diagnostic reports tend to be comprehensive which set them apart from past piecemeal studies. The reports are exclusively dedicated to exploring criminal justice issues without mixing them up with other justice reform questions. New topics such as reparation schemes for violations of human rights during criminal proceedings and transitional justice are made part of the diagnostic study.

The claim for comprehensiveness of the research reports should nevertheless be taken with a pinch of salt. The reports are far from being complete covering every conceivable dimension of criminal justice. They have inevitably left multitude of questions un-researched. Few of them can be mentioned here. Degree of police coercion, public trust in the criminal justice system, juvenile justice, crime prevention strategy, role of customary criminal justice practices, rules and institutions, the relationship between criminal justice and politics, etc are issues awaiting researchers.

\section{Some observations}

\section{a) Taking implementation of law reform with a pinch of salt:}

The AC and WG are expected to have some kind of role in the implementation of legislation or research-based reform measures that they suggest to the Government. This sounds good. Karl Marx has famously remarked that "The philosophers have only interpreted the world, in various ways. The point, however, is to change it." So far the Ethiopian criminal justice system has been researched including by the WG; the key point is to actually change it for the good of citizens, in ways that positively contribute to the prevalence of human rights, the rule of law and democracy. However, it appears that the modus operandi of the implementation face of the 
ongoing reform arrangement has been left prominently dwarfed by preparing draft legislation and undertaking diagnostic studies. This side thus remains un-clarified.

The question of implementation is a material concern for the WG. The Prison Proclamation is out. ${ }^{16}$ Seven diagnostic studies are finalized. ${ }^{17}$ The CPEC is on the verge of parliamentary adoption. Hence, the business of implementation looms large and clear. Undoubtedly, implementation entails mobilization of resources to ensure that relevant officials and experts have properly digested the nature and underlying assumptions of the two bills and the recommendations emanating from the diagnostic studies. Beyond being fully understood, there is a need to check that the bills and research recommendations are being actually translated into action. The actual implementation effort doubtlessly requires knowledge of and skills in substantive and procedural criminal law, and proper understanding of the workings of the pertinent institutions; equally important in the implementation schema is disposition on the part of the WG to connect with the personnel working at criminal law enforcement institutions.

However, I believe the roles of both the AC and WG in the implementation phase of the law reform are least articulated. To my understanding, a sensible starting point for implementation of the recommendations of the studies is to develop an implementation plan to be refined and endorsed by the $\mathrm{AC}$ and perhaps by the leadership of core criminal justice enforcement institutions. The implementation plan should cover, on the top of recommendations emanating from the studies, the two pieces of legislation mentioned above to the enactment of which the WG contributed so much. Attempting to bring the $\mathrm{AC}$ and these institutions on the same wavelength by organizing a platform for them to contribute to and validate the findings and recommendations of the diagnostic studies can be one of the activities to be included in the implementation plan.

In terms of approach, I think, by any standard, the role to be played by $\mathrm{AC}$ through its WG is not to actually implement its own reform

16 The WG has witnessed a sign of hope in the leadership of the Federal Prison Commission, who appear to be quite receptive of changing the attitude of the prison apparatus towards prisoners and their human rights and dignity. However, it is doubtful if there is the same level of enthusiasm for reform proposals coming from the WG on the part of expert level at the institution.

17 The diagnostic study on transitional justice - started being implemented in its own way - hopefully would lead to revision of the proclamation that has established the Reconciliation Commission. The lead researcher of the WG regarding transitional justice is also leading the revision of such a proclamation. 
recommendations and bills but to act as a facilitator, offer technical support and perhaps follow up the implementation of those reform ideas by the concerned institutions. A pushy approach to implementation of the reform measures would lead the AC to clash with institutions which tend to zealously guard their mandate. It would not be helpful.

On the contrary, sticking to a loose implementation approach which is confined to organization of seminars on the laws and diagnostic studies to the relevant institution would be less effective. Under this approach, the reform initiative would solely be confined to knowledge generation.

A middle ground could be forged which includes bringing decision makers and key experts from the relevant institutions fully on board by making them understand and embrace the suggested policy, legal and administrative reform measures. Design of the middle ground should take the following factors into account: nature and history of the particular legislative drafting process, extent of reform receptivity of the leadership of and experts at the relevant institutions and their degree of involvement in the law reform and research process sought to be implemented. For instance, the WG has attempted to involve experts from relevant criminal justice institutions, as contributors, participants and informants, in the course of conducting the diagnostic studies. However, the WG thinks that the degree of participation involved in this regard was not adequate.

The AC needs to give serious thought to the approach and content of implementation reform recommendations and legislation. If the implementation stage is taken lightly, some law reform measures could easily be undone through legislative amendment or selective implementation or by issuing non-compliance regulation or directives, or resorting to a combination of these. In doing so, the relevant authorities can invent multitude of excuses to ultimately defeat or dilute the rigors of the reform program. The forces of inertia within government bureaucracy may be stronger and more entrenched than those of change.

\section{b) Responsible consideration of law reform advice}

Frank discussion is needed on the level of expectation of acceptance of reform proposals forwarded by the $\mathrm{AC}$ through its WG. The $\mathrm{AC}$ is there to advice, as the name suggests. The advice on a given law reform measure may be based on well considered opinions and studies. Given this, the AC expects its advice to be taken seriously and responsibly by the Government; the government is at liberty to reject or modify the advice; but that should be done with good reasons. That should also be done transparently; continued engagement with members of $\mathrm{WG}$ who toil on the reform proposal is advisable. 
But the WG should note that the service it provides is advising, not making a final decision. It should also note that there are so many actors in the decision making process on the government side. These organs include the AG, Council of Ministers, HoPR and an implementing institution. The reform bill might involve other critical government institutions in multisectoral laws, which is often the case. It is to be noted that each of them might have genuinely differing perspectives on a given law reform issue.

This issue of the WG's expectation of acceptance on the part of the Government to whom advice is offered is raised here with a good reason. The issue arose in connection with the Draft CPEC. In the AG's final round of internal review, several provisions the WG (included in the Draft CPEC in the form of substantive and procedural safeguards, e.g., provisions on bail and frequency of adjournments for police investigation, admissibility of evidence and plea bargaining) were thought to have been made lax in favor of the police and the prosecution implying some reform backsliding as some of these spots being very sensitive and source of public uproar in the past.

However, the extent and nature of reform retraction in connection with the Draft Code cannot be ascertained at this stage. Now the bill is with the HoPR. It is hoped that this last phase of the legislative process would not be rushed. The draft law is already triggering intense debates and consultations by various institutions within and outside the government. Some members of the WG are seen to have been involved in explaining and refining the provisions of the draft document. The HoPR has already conducted one public consultation. However, the broader issue considered here remains. I suspect the question of the need for responsible consideration of reform ideas may have arisen in connection with law reform proposals forwarded by other working groups as well.

\section{c) Alignment of law reform efforts}

The WG witnessed lack of reform alignments among relevant criminal justice institutions. During the period of writing the research reports of the WG, several government institutions have been conducting independent studies of their own on the very issues the WG was researching. Many nongovernment institutions have also ventured into a similar research activity. Multiplicity of law reform initiatives are carried out at the same time by many actors with the motive to exercise institutional mandates and competition for resources including donor funding. Non-aligned law reform efforts are driven both institutionally and externally. In the process, concepts like coordination, integration and reform alignments become rhetoric. This suggests the need to carefully examine the advisability of entertaining duplicate and parallel reform initiatives. To put it straightforwardly, it seems 
to me sound to inquire whether it is feasible to centralize law reform in the setting where law reform is taking place at large scale and faster pace.

\section{d) Technocratic versus public consultation}

In Ethiopia's ongoing reform, public consultation is made a perquisite in the process of any law reform proposal or a diagnostic study. Public consultation is presented as a mark which distinguishes current law reform from past exercise of the same kind. This is indeed commendable. In introducing public consultation, the idea seems that law reform initiatives should move beyond institutional and professional circles to be inclusive of ordinary citizens. Citizens have the right to be consulted in matters that affect them. Meaningful consultation has an instrumental value; it is thought to aid in the implementation of law reform.

The spirit of this movement away from technocratic approach to law reform is laudable. Yet, the concept of public consultation needs to be further explored. There seems to be lack of uniform understanding of public consultation. Under misconstrued approaches in the organization of public consultation, there is a tendency to fall back to the habit of consultation among technocrats, rather than authentic involvement of citizens. Whether we have actually moved an inch from technocratic approach to law reform craft is an issue which requires exploring.

\section{e) Inscribing law reform memory}

Ethiopia's attempt to obtain inputs from experts pro bono cum public model is a new experiment. This paradigm has brought about a spate of foundational legislative reforms with consequential impact on human rights, democracy, democratic institutions, the rule of law and economic order. It has allowed law experts to peep the working of the government; it a potential for indigenization of law reform. It is sound to appreciate the underlying principles, values, contribution to development and legitimacy of the legal system of these law reform measures.

It is high time to engage in a proper documentation of the processes of such legislative initiatives and diagnostic studies, national, regional and international actors involved therein, and objectives pursued by each of them. Inscribing the contents of the law reform endeavour alone is insufficient although it is necessary. It is trite to say that documentation of the process and forces which took part in it is part and parcel of the legal history of the country. In the absence of documentation, individual memories would fade; documents might scatter; critical forces could disperse or some of them loose interest soon. It would lead to loss of a critical bit of the institutional memory of the legal system of the country as whole. 


\section{Concluding Remarks: Gratitude to Kind Souls}

The ongoing law reform initiative of Ethiopia has revealed to me that there are so many legal professionals who are on the giving end if harnessed wisely. It is a country of professionals on the giving rather than receiving end. It is time to record gratitude to these kind souls. Several people and institutions cooperated with the WG in good spirit. Appreciation goes to colleagues who moderated sessions, made presentations, provided written suggestions.

Moreover, credit should go to institutions that funded some of our activities and most importantly colleagues who did actual research and drafted legislation. Gratitude is extended to Lawyers for Human Rights which covered communication and transportation cost for members of the write-up as well as covering expenses attendant to the two-day public consultation on the diagnostic studies. We are also grateful to the Ethiopian Lawyers Association that managed external funding that covered the cost for some of the WG's workshops. The WG remains appreciative of all other individuals and institutions that helped the realization of its work plans. The WG is eternally thankful to you all.

Muradu Abdo (Chair, Criminal Justice Reform Working Group)

December 2020 